\title{
Peginterferon alfa-2b and ribavirin therapy in Kuwaiti patients with chronic hepatitis $C$ virus infection
}

\author{
S.A. Al-Enzi, ${ }^{7}$ W.A. Ismail, ${ }^{2}$ S.A. Alsurayei ${ }^{7}$ and A.E. Ismail ${ }^{2}$
}

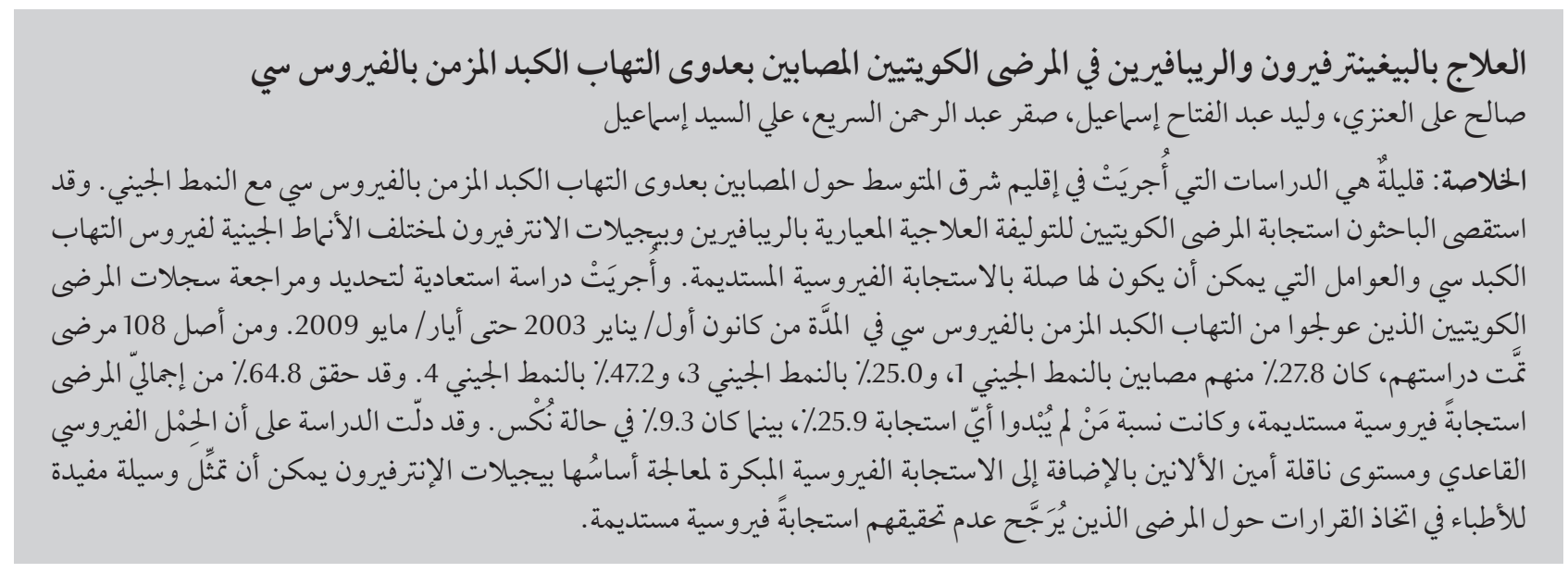

ABSTRACT Few studies have been conducted in the Eastern Mediterranean region on chronic hepatitis $\mathrm{C}$ virus (HCV) infection with reference to genotypes. We investigated the response to standard combination therapy (pegylated interferon/ribavirin) of different genotypes of HCV in Kuwaiti patients and factors that could be associated with sustained virological response (SVR). The records of all Kuwaiti patients treated for chronic HCV between January 2003 and May 2009 were retrospectively identified and reviewed. Of 108 patients studied, $27.8 \%$ were infected with genotype 1, 25.0\% with genotype 3 and 47.2\% with genotype 4 . Overall, 64.8\% of patients achieved SVR, 25.9\%, were non-responders and 9.3\% were relapsers. Baseline viral load and alanine aminotransferase level in addition to early virological response to pegylated interferon-based therapy may serve as a decision tool for clinicians to identify patients who are unlikely to achieve SVR.

Traitement par peginterféron alfa-2b et ribavirine chez des patients koweïtiens atteints d'infection chronique par le virus de I'hépatite $C$

RÉSUMÉ Peu d'études ont été conduites dans la région de la Méditerranée orientale sur l'infection chronique par le virus de l'hépatite $C$ rapportée aux différents génotypes. Nous avons étudié la réponse à une association médicamenteuse classique (interféron pégylé/ribavirine), de différents génotypes du virus de I'hépatite $C$ chez des patients koweïtiens, et les facteurs qui pourraient être associés à une réponse virologique prolongée. Les dossiers de tous les patients koweïtiens traités pour une infection par le virus de l'hépatite C entre janvier 2003 et mai 2009 ont été recherchés et examinés. Parmi 108 patients étudiés sur dossier, 27,8 \% d’entre eux étaient infectés par le génotype 1, 25,0 \% par le génotype 3, et 47,2 \% par le génotype 4. Globalement, 64,8 \% des patients ont présenté une réponse virologique prolongée, 25,9\% étaient non-répondeurs et 9,3\% ont rechuté. La charge virale de référence et le taux d'alanine aminotransférase, associés à une réponse virologique précoce au traitement à base d'interféron pégylé sont des critères qui pourraient servir d'aide à la décision pour les cliniciens afin d'identifier les patients qui ne sont pas susceptibles de présenter une réponse virologique prolongée. 


\section{Introduction}

Chronic hepatitis $\mathrm{C}$ virus (HCV) infection affects about $3 \%$ of the world's population [1]. In the Eastern Mediterranean region, with a population of 446 million, the World Health Organization estimates of the prevalence of $\mathrm{HCV}$ infection range from $1.0 \%-4.6 \%$, with 21.3 million people infected with the disease [2]. Up to $85 \%$ of these individuals develop chronic HCV infection, which can progress to cirrhosis, endstage liver disease and hepatocellular carcinoma [3]. The standard of care for the treatment of chronic HCV is a combination therapy with pegylated interferon and ribavirin [4]. Pegylated interferon (PEG-INF) is a synthetic variant of interferon- $\alpha$, a naturally occurring cytokine whose endogenous role is to activate the innate immune response. Ribavirin (RBV) is a nucleoside analogue that is thought to act through a combination of modalities $[5,6]$. This combination therapy, however, shows significantly different response rates for the various $\mathrm{HCV}$ genotypes.

There are 6 major HCV genotypes, numbered from 1 to 6 . Genotype 2 is the most responsive, with a sustained virological response (SVR) rate greater than $80 \%[7,8]$. The most prevalent genotype worldwide, genotype 1 , is the least responsive. Various studies have reported SVR in $42 \%-46 \%$ of patients infected by HCV genotype 1 and 60\% in patients infected by $\mathrm{HCV}$ genotype 4 [9-13]. HCV genotypes have been associated with specific geographical areas. In developed countries, genotype determination has formed a part of the management of patients with $\mathrm{HCV}$ infection. The epidemiology of $\mathrm{HCV}$ has been shown to be changing rapidly in many countries due to population movement and different lifestyles [14].

Various factors have been associated with response to treatment of chronic hepatitis $\mathrm{C}$ including viral factors, such as viral genotype, pretreatment viral load and early virological response (EVR), individual patient characteristics, such as age, sex, liver fibrosis and body mass index, and interferon regimen [6,9,1517]. Nevertheless, few studies have been conducted in the Eastern Mediterranean region on chronic $\mathrm{HCV}$ with reference to genotypes [18]. In Kuwait, although there is some data recording the prevalence of HCV genotypes [19] studies have been only conducted to assess the efficacy of combined therapy on HCV genotype 4 [20-22].

The aim of the present study was to investigate the response to treatment with standard combination therapy of the different genotypes of $\mathrm{HCV}$ in $\mathrm{Ku}$ waiti patients and factors that could be associated with SVR.

\section{Methods}

\section{Setting and design}

The study design was a retrospective records-based study in Farwaniya hospital, which has 1000 beds and is one of 5 general government hospitals which provide secondary health care in Kuwait. The study was conducted after approval from the ethical committee of the Ministry of Health. The study population was recruited from the records of the hepatology outpatient clinic, where evaluation and treatment of patients with suspected HCV were applied by the treating physicians according to the standard protocol of the hospital. According to this protocol, patients should be investigated for serum alanine aminotransferase (ALT) and aspartate aminotransferase (AST). Also, Anti-HCV antibody should be assessed by a second-generation enzyme-linked immunosorbent assay. HCV-RNA is detected by polymerase chain reaction (PCR) using Cobas Amplicor HCV monitor, version 2.0 (Roche Diagnostics), and is confirmed as compensated liver disease by clinical, biochemical and imaging findings. The HCV genotype is determined using a line-probe assay
(INNO-LiPA HCV, Innogenetics). Liver biopsy is done when indicated.

The protocol includes treatment of all patients by PEG-INF $\alpha$-2b (PegIntron, Schering-Plough) $1.5 \mathrm{mg} / \mathrm{kg}$ body weight weekly plus RBV (Rebetol, Schering-Plough) $800 \mathrm{mg} /$ day for body weight $<65 \mathrm{~kg} ; 1000 \mathrm{mg} /$ day for body weight between $65-85 \mathrm{~kg}$; and $1200 \mathrm{mg} /$ day for body weight $>85 \mathrm{~kg}$. Patients with genotype 3 disease receive treatment for 24 weeks while patients with genotype 1 or 4 disease receive treatment for 48 weeks. All patients are evaluated by their treating physician during office visits with blood tests at regular intervals during treatment and followed up for 24 weeks after cessation of therapy.

\section{Patients}

The records of all native Kuwaiti patients treated for chronic $\mathrm{HCV}$ between January 2003 and May 2009 were retrospectively identified and reviewed. Inclusion criteria included adult, Kuwaiti patients aged $\geq 18$ years, with elevated ALT at least 2 times the upper limit of normal on at least 2 occasions, detectable anti-HCV antibody status, detectable HCV-RNA, and demonstration of compensated liver disease by clinical, biochemical and imaging findings. Viral load was considered high if HCV-RNA $\geq 600000 \mathrm{IU} / \mathrm{mL}$ and low if $<600000$ $\mathrm{IU} / \mathrm{mL}$.

Patients were excluded from the study if they had other liver diseases, such as hepatitis A, hepatitis B, schistosomiasis, autoimmune hepatitis, alcoholic liver disease, drug induced hepatitis, decompensated liver disease or other comorbid conditions such as coinfection withHIV, neoplastic disease, severe cardiac or pulmonary disease, unstable thyroid dysfunction, psychiatric disorder, organ transplant, therapy with immunomodulatory agents, neutropenia $\left(<1500\right.$ neutrophils $\left./ \mathrm{mm}^{3}\right)$, anaemia (haemoglobin $<12 \mathrm{~g} / \mathrm{dL}$ ), thrombocytopenia ( $<90000$ platelets/ $\mathrm{mm}^{3}$ ), creatinine concentration $>1.5$ 
times the upper limit of normal, serum a-fetoprotein concentration $>25 \mathrm{ng} /$ $\mathrm{mL}$, pregnancy or breastfeeding.

Of 127 patient records reviewed, 19 were excluded for different causes and so 108 patients fulfilled the inclusion criteria. Patients were classified into 2 groups according to the SVR. The first group was patients without SVR (cases) who were those with non-response, those who relapsed after end-of-treatment response (ETR) and those for whom treatment was discontinued either due safety reasons (presence of a treatment-related adverse event requiring withdrawal from therapy) or nonsafety reasons (refusal of treatment or non-cooperation from the patient). The second group was patients who had SVR (controls).

\section{Data collection}

Other data for the study were recorded on a special data collection form. These included personal characteristics [age, sex, body mass index (BMI) and source of infection] and clinical information (antiviral therapy, response to treatment and adverse events) in addition to laboratory investigations (HCV genotype, viral load, ALT and AST levels, complete blood picture and thyroid function tests).

\section{Assessment of efficacy}

EVR was defined as a 2-log 10 drop in $\mathrm{HCV}$ viral load by week 12 as compared to baseline values. Treatment was stopped if there was no EVR or if HCV-RNA was detected at week 24 by PCR. ETR was defined as an undetectable HCV viral load at the end of the treatment course. SVR was defined as an undetectable HCV viral load 6 months after the end of treatment and was considered the primary outcome. All patients who dropped out due to adverse side-effects were considered as nonresponders.

\section{Statistical analysis}

Simple descriptive statistics were used [median with interquartile range (IQR) for quantitative variables and number with percentage for categorical ones]. Analysis was initially carried out based on a series of univariate comparisons. In order to control simultaneously for possible confounding effects of the variables, multiple logistic regression was used for the final analysis. In the univariate analysis the chi-squared test was used to detect the association between SVR and explanatory variables. In multiple logistic regression analysis, the association between exposure and outcome was expressed in terms of odds ratio (OR) and their 95\% confidence intervals (CI).

All the explanatory variables included in the logistic model were categorized into 2 or more levels: sex (male, female); age at diagnosis $(<30$, 30-39, > 40 years); BMI group (normal, underweight, overweight/obese); mode of infection (medical, personal, unknown); genotype (1,3,4); viral load (low, high); ALT times normal level: (2-2.49, 2.5-2.99, > 3); AST times normal level (2-2.49, 2.5-2.99, > 3); EVR (no, yes). Analysis was performed using SPSS, version 11.0.

\section{Results}

\section{General characteristics of patients}

Of 108 studied patients with HCV infection, 30 (27.8\%) patients were infected with genotype 1, 27 (25.0\%) with genotype 3 and 51 (47.2\%) with genotype 4 . A total of 58 patients were male (53.7\%). The median age was 39 (IQR 14.5) years. About half of patients had normal BMI (48.1\%) and 39.8\% were overweight or obese. The mode of infection was due to blood transfusion or a medical procedure in $25.1 \%$ of cases or to occupational exposure or contact in $11.1 \%$ (unknown in $64.8 \%$ of patients).

\section{Virological response}

Overall 70 patients (64.8\%) had SVR, 28 patients were non-responders (25.9\%) and 10 patients were relapsers (9.3\%). The corresponding figures were $46.7 \%, 40.0 \%$ and $13.3 \%$ in genotype 1 , $81.5 \%, 11.1 \%$ and $7.4 \%$ in genotype 3 , and $66.7 \%, 25.5 \%$ and $7.8 \%$ in genotype 4. No significant difference could be detected among different genotypes in terms of the final outcome $\left(\chi^{2}=8.04, P\right.$ $=0.09)$ (Table 1$)$.

As shown in Figure 1, in genotype 1, 18 patients had EVR. A single patient dropped out and 17 had ETR. Of them, 3 patients were relapsed and 14 patients had SVR (77.8\% among EVR).

In genotype 3, 24 patients had EVR. All of them had ETR. Of them, 2 patients were relapsers and 22 patients had SVR (91.7\% among EVR).

In genotype 4, 41 patients had EVR. Three patients dropped out and $38 \mathrm{had}$ ETR. Of them, 4 patients were relapsers and 34 patients had SVR (82.9\% among EVR).

\section{Biochemical response}

Overall, the median level of ALT dropped significantly from 130 to 33 IU/L (74.6\% decrease) and AST from 94 to $43 \mathrm{IU} / \mathrm{L}$ ( $54.3 \%$ decrease) after 72 weeks. Analysing the genotypes 1 , 3 and 4 separately also showed that the levels of both enzymes dropped significantly after 72 weeks (Table 2).

\section{Factors associated with SVR}

A total of $70 \mathrm{HCV}$ patients with SVR were compared with 38 patients without SVR. Male sex, age < 30 years and normal BMI were more frequent in the SVR group; however, none of these personal factors reached statistical significance (Table 3).

Analysing the clinical factors, genotype 3 and 4 were significantly associated with SVR (31.4\% versus 13.2\%, $P=0.02)$. SVR was significantly more likely in patients with low baseline viral 


\begin{tabular}{|c|c|c|c|c|c|c|c|c|}
\hline \multirow[t]{2}{*}{ Outcome } & \multicolumn{2}{|c|}{ Genotype 1} & \multicolumn{2}{|c|}{ Genotype 3} & \multicolumn{2}{|c|}{ Genotype 4} & \multicolumn{2}{|c|}{ Total } \\
\hline & No. & $\%$ & No. & $\%$ & No. & $\%$ & No. & $\%$ \\
\hline Sustained virological response & 14 & 46.7 & 22 & 81.5 & 34 & 66.7 & 70 & 64.8 \\
\hline Non-response & 12 & 40.0 & 3 & 11.1 & 13 & 25.5 & 28 & 25.9 \\
\hline Relapse & 4 & 13.3 & 2 & 7.4 & 4 & 7.8 & 10 & 9.3 \\
\hline Total & 30 & 100.0 & 27 & 100.0 & 51 & 100.0 & 108 & 100.0 \\
\hline
\end{tabular}

load $(54.3 \%$ versus $13.2 \%)(P<0.001)$, lower levels of baseline ALT and AST $(P=0.02, P<0.001$ respectively $)$ and EVR $(95.4 \%$ versus $42.1 \%)(P<0.001)$ (Table 4).

Results of multivariate logistic regression analysis revealed that $\mathrm{HCV}$ patients with high baseline viral load were more liable to be non-responders ( $\mathrm{OR}=5.2,95 \% \mathrm{CI}: 3.4-17.3)$, as were those with higher levels of baseline ALT ( $\geq 3$ times normal level) versus 2.5 times normal level) $(\mathrm{OR}=6.8,95 \%$ CI: 4.1-11.6). Patients who had EVR were less liable to be non-responders $(\mathrm{OR}=0.2,95 \%$ CI: 0.1-0.3) (Table $5)$.

\section{Safety and tolerability}

As shown in Table 6, overall the most common adverse events of therapy were flu-like symptoms (50.0\%), pruritus $(25.9 \%)$, anaemia (16.7\%), fatigue (16.7\%) and depression (15.7\%). The corresponding figures for each genotype are also shown in Table 6.

In genotype 1, 3 patients (10\%) were withdrawn from treatment; 2 patients due to severe pruritus (at weeks 11 and 12) and 1 patient who developed febrile neutropenia at week 8 which was adequately treated. The dose of PEG-INF was reduced in 1 patient due to neutropenia, and RBV dose adjustments were necessary in 2 patients due to anaemia.
Among genotype 3, PEG-INF was reduced per protocol in 1 patient due to neutropenia.

Among genotype 4, therapy was discontinued in 2 patients (3.9\%) due to a severe depressive state at week 16 and 6 patients needed antidepressant medication to continue the therapy. The dose of PEG-INF was reduced as per the protocol in 5 patients due to neutropenia or thrombocytopenia. The dose of RBV was reduced per protocol in 7 patients due to anaemia.

There were no unusual adverse events reported during this study and no growth factors were used. None of patients developed decompensation and no deaths were reported during therapy or follow-up.
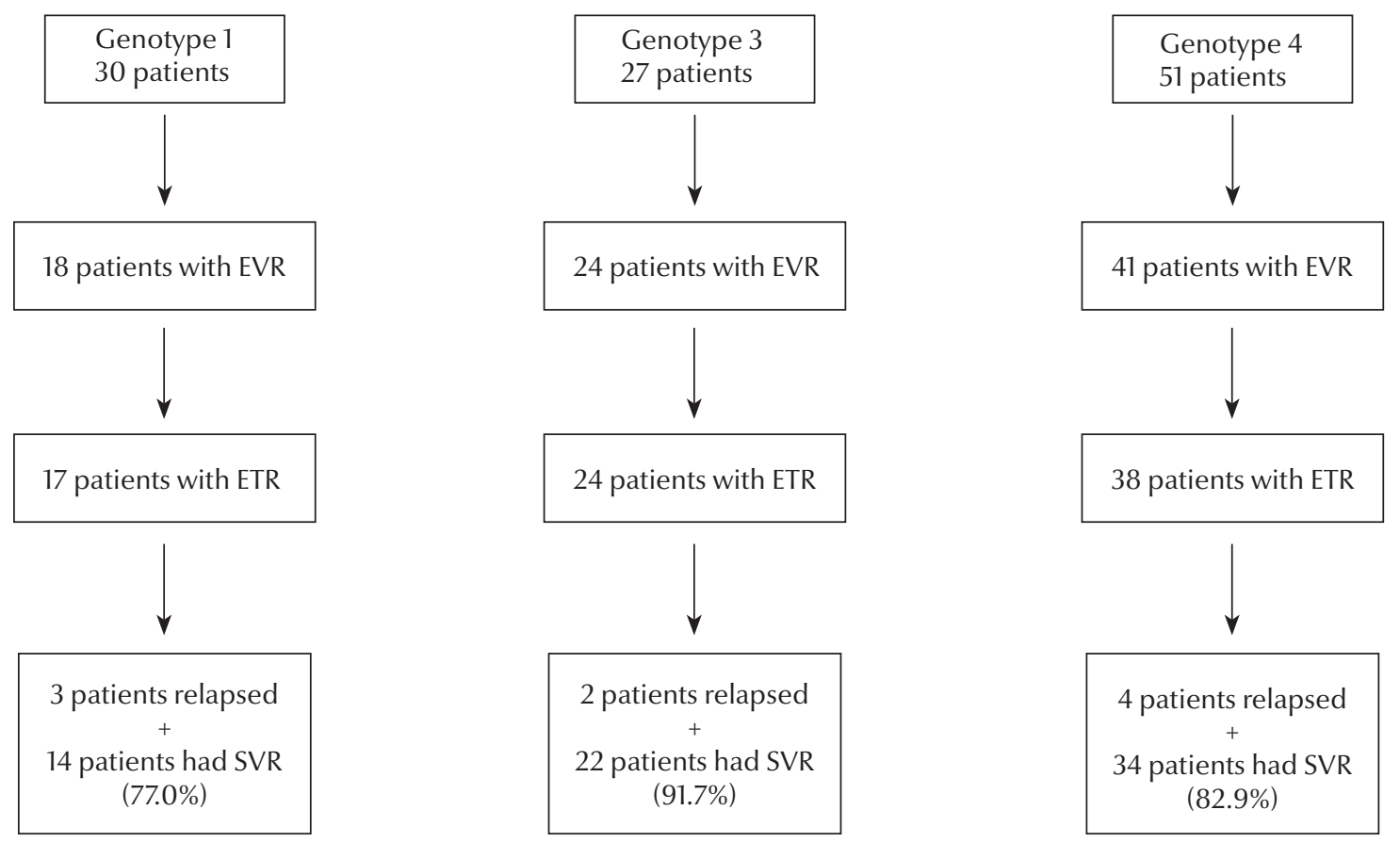

Figure 1 Virological response of patients with hepatitis $C$ virus infection by genotype $S V R=$ sustained virological response; $E T R=$ early virological response; $E T R$ = end-of-treatment response 


\begin{tabular}{|c|c|c|c|c|}
\hline \multirow[t]{2}{*}{ Reading } & Genotype 1 & Genotype 3 & Genotype 4 & Overall \\
\hline & Median (IQR) & Median (IQR) & Median (IQR) & Median (IQR) \\
\hline \multicolumn{5}{|c|}{ ALT level $(I U / L)$} \\
\hline Baseline & 159 (95) & $85(76)$ & $136(94)$ & $130(95)$ \\
\hline 72 weeks & $36(52)$ & $0(0)$ & $45(52)$ & $33(48)$ \\
\hline$z$-test & 4.74 & 4.54 & 6.19 & 8.98 \\
\hline$P$-value & $<0.001$ & $<0.001$ & $<0.001$ & $<0.001$ \\
\hline \multicolumn{5}{|c|}{ AST level $(I U / L)$} \\
\hline Baseline & $84(33)$ & $96(40)$ & $102(48)$ & $94(43)$ \\
\hline 72 weeks & $33(39)$ & $0(0)$ & $45(51)$ & $34(45)$ \\
\hline$z$-test & 4.77 & 4.54 & 5.61 & 8.79 \\
\hline$P$-value & $<0.001$ & $<0.001$ & $<0.001$ & $<0.001$ \\
\hline
\end{tabular}

$I Q R=$ interquartile range; $A L T=$ alanine aminotransferase; $A S T=$ aspartate aminotransferase.

\section{Discussion}

Patients chronically infected with HCV require significantly different durations of therapy and achieve substantially different SVR rates to therapy depending on the HCV genotypes with which they are infected [23]. To our knowledge, this is the first report from Kuwait to assess the efficacy and safety of the standard combination therapy in chronic $\mathrm{HCV}$ infection and predictors of SVR to combined therapy in different genotypes.

Ourstudy showed a predominance of genotype 4 (47.9\%) followed by genotype 1 (27.3\%) and genotype 3 (24.6\%) in the study population. In a previous study that was conducted in Kuwait, Pacsa et al found, within the typable HCV, a comparable prevalence of genotype-4 (38\%) and genotype-1 (27\%) with a relatively lower prevalence of HCV genotype-3 (9\%) in Kuwaiti nationals [19]. The increase in the frequency of HCV genotype-3 in the present study may be attributed to the increase in the migrant population density from genotype-3 areas such as Pakistan, Bangladesh and Iran in Kuwait and this may have an impact on the molecular epidemiology of $\mathrm{HCV}[24,25]$. The variation may also be attributed to a certain degree to HCV accumulated mutation. In

\begin{tabular}{|c|c|c|c|c|c|c|}
\hline \multirow[t]{3}{*}{ Variable } & \multicolumn{4}{|c|}{ Sustained virological response } & \multicolumn{2}{|c|}{ Statistical significance } \\
\hline & \multicolumn{2}{|c|}{$\begin{array}{c}\text { No } \\
(n=38)\end{array}$} & \multicolumn{2}{|c|}{$\begin{array}{c}\text { Yes } \\
(n=70)\end{array}$} & \multirow[b]{2}{*}{$x^{2}$ test } & \multirow[b]{2}{*}{$P$-value } \\
\hline & No. & $\%$ & No. & $\%$ & & \\
\hline \multicolumn{7}{|l|}{ Sex } \\
\hline Male & 18 & 47.4 & 40 & 57.1 & 0.95 & 0.33 \\
\hline Female & 20 & 52.6 & 30 & 42.9 & & \\
\hline \multicolumn{7}{|l|}{ Age (years) } \\
\hline$<30$ & 4 & 10.5 & 15 & 21.4 & 2.46 & 0.92 \\
\hline $30-39$ & 16 & 42.1 & 22 & 31.4 & & \\
\hline$\geq 40$ & 18 & 47.4 & 33 & 47.1 & & \\
\hline \multicolumn{7}{|l|}{ BMI group } \\
\hline Normal & 14 & 36.8 & 38 & 54.3 & 17.09 & 0.06 \\
\hline Underweight & 8 & 21.1 & 5 & 7.1 & & \\
\hline Overweight/obese & 27 & 42.1 & 27 & 28.6 & & \\
\hline \multicolumn{7}{|l|}{ Mode of infection } \\
\hline Medical & 11 & 28.9 & 15 & 21.4 & 2.39 & 0.30 \\
\hline Personal & 2 & 5.3 & 10 & 14.3 & & \\
\hline Unknown & 25 & 65.8 & 45 & 64.3 & & \\
\hline
\end{tabular}

$B M I=$ body mass index 


\begin{tabular}{|c|c|c|c|c|c|c|}
\hline \multirow[t]{3}{*}{ Variable } & \multicolumn{4}{|c|}{ Sustained virological response } & \multicolumn{2}{|c|}{ Statistical significance } \\
\hline & \multicolumn{2}{|c|}{$\begin{array}{c}\text { No } \\
(n=38)\end{array}$} & \multicolumn{2}{|c|}{$\begin{array}{c}\text { Yes } \\
(n=70)\end{array}$} & \multirow[b]{2}{*}{$x^{2}$ test } & \multirow[b]{2}{*}{$P$-value } \\
\hline & No. & $\%$ & No. & $\%$ & & \\
\hline \multicolumn{7}{|l|}{ Genotype } \\
\hline 1 & 16 & 42.1 & 14 & 20.0 & 7.70 & 0.02 \\
\hline 2 & 5 & 13.2 & 22 & 31.4 & & \\
\hline 3 & 17 & 44.7 & 34 & 48.6 & & \\
\hline \multicolumn{7}{|c|}{ Viral load (PCR) } \\
\hline Low & 5 & 13.2 & 38 & 54.3 & 17.39 & $<0.001$ \\
\hline High & 33 & 86.8 & 32 & 45.7 & & \\
\hline \multicolumn{7}{|c|}{ ALT $(\times$ normal level $)$} \\
\hline $2-2.49$ & 7 & 18.4 & 30 & 42.9 & 8.36 & 0.02 \\
\hline $2.5-2.99$ & 13 & 34.2 & 23 & 32.9 & & \\
\hline$\geq 3$ & 18 & 47.4 & 17 & 24.3 & & \\
\hline \multicolumn{7}{|c|}{ AST ( $\times$ normal level) } \\
\hline $2-2.49$ & 19 & 50.0 & 44 & 63.8 & 23.24 & $<0.001$ \\
\hline $2.5-2.99$ & 11 & 28.9 & 21 & 30.4 & & \\
\hline$\geq 3$ & 8 & 21.1 & 4 & 5.8 & & \\
\hline \multicolumn{7}{|c|}{ Early virological response } \\
\hline No & 22 & 57.9 & 3 & 4.3 & 39.79 & $<0.001$ \\
\hline Yes & 16 & 42.1 & 66 & 95.4 & & \\
\hline
\end{tabular}

$P C R=$ polymerase chain reaction; $A L T=$ alanine aminotransferase $; A S T=$ aspartate aminotransferase .

a recent study in Saudi Arabia, it was found that $55.6 \%$ of HCV patients had genotype 4, 12.3\% had genotype 2 or 3 and $21.8 \%$ had genotype 1 [18]. This is in strong contrast to the situation in Egypt, where more than 90\% of chronic HCV cases are caused by genotype 4 [26].

\begin{tabular}{|c|c|}
\hline $\begin{array}{l}\text { Table } 5 \text { Facto } \\
\text { multivariate }\end{array}$ & nse: results of \\
\hline Variable & OR $(95 \% \mathrm{Cl})$ \\
\hline Viral load & \\
\hline Low & $1^{a}$ \\
\hline High & $5.2(3.4-17.3)$ \\
\hline Early virolog & \\
\hline No & $1^{a}$ \\
\hline Yes & $0.2(0.1-0.3)$ \\
\hline Baseline ALT & \\
\hline $2-2.49$ & $1^{a}$ \\
\hline 2.5-2.99 & $3.9(0.9-7.3)$ \\
\hline$\geq 3$ & $6.8(4.1-11.6)$ \\
\hline
\end{tabular}

${ }^{a}$ Reference category.

$O R=$ odds ratio; $C I=$ confidence interval; $A L T=$ alanine aminotransferase.
The current study revealed an overall SVR rate of $64.8 \%$ among patients with HCV after combined therapy of PEG-INF/RBV. The rate of SVR was $46.7 \%$ in genotype $1,81.5 \%$ in genotype 3 , and $66.7 \%$ in genotype 4 . This is in accordance with the rates found by Al-Ashgar et al. in Saudi patients [18].

However, the rate of SVR in our study was higher regarding genotype 3 . To a certain degree, our rates of SVR are higher than those found in some other previous studies [12,13,27-29]. This may be due different population characteristics and the impact of different inclusion and exclusion criteria in other studies. For example, patients with liver diseases were excluded from the current study. Most of those patients, if included, would be expected to add to the non-response group, thereby decreasing the rates of SVR [21]. Another study conducted in Kuwait and another one in France showed that patients with severe fibrosis were less likely to respond than other patients $[21,30]$. Also, the relatively young median age in the current study may enhance their response $[18,31]$. In accordance with our results, others have reported that Asian patients with chronic HCV achieve higher rates of SVR compared with non-Asian patients, particularly those with genotype 


\begin{tabular}{|c|c|c|c|c|c|c|c|c|}
\hline \multirow[t]{2}{*}{ Side-effects } & \multicolumn{2}{|c|}{ Genotype 1} & \multicolumn{2}{|c|}{ Genotype 3} & \multicolumn{2}{|c|}{ Genotype 4} & \multicolumn{2}{|c|}{ Overall } \\
\hline & No. & $\%$ & No. & $\%$ & No. & $\%$ & No. & $\%$ \\
\hline Flue-like & 12 & 40.0 & 16 & 59.3 & 26 & 51.0 & 54 & 50.0 \\
\hline Itching/rash/pruritus & 9 & 30.0 & 5 & 18.5 & 14 & 27.5 & 28 & 25.9 \\
\hline Anaemia & 2 & 6.7 & 4 & 14.8 & 12 & 23.5 & 18 & 16.7 \\
\hline Fatigue & 4 & 13.3 & 7 & 25.9 & 7 & 13.7 & 18 & 16.7 \\
\hline Depression & 7 & 23.3 & 4 & 14.8 & 6 & 11.8 & 17 & 15.7 \\
\hline Weight loss & 3 & 10.0 & 7 & 25.9 & 7 & 13.7 & 17 & 15.7 \\
\hline Hair loss & 7 & 23.3 & 0 & 0.0 & 5 & 9.8 & 12 & 11.1 \\
\hline Anorexia & 9 & 30.0 & 2 & 7.4 & 1 & 2.0 & 12 & 11.1 \\
\hline Insomnia & 5 & 16.7 & 0 & 0.0 & 6 & 11.6 & 11 & 10.2 \\
\hline Leucopenia & 3 & 10.0 & 2 & 7.4 & 5 & 9.8 & 10 & 9.3 \\
\hline Arthralgia/myalgia & 0 & 0.0 & 2 & 7.4 & 4 & 7.9 & 6 & 5.5 \\
\hline Nausea & 2 & 6.7 & 0 & 0.0 & 3 & 5.9 & 5 & 4.6 \\
\hline Pyrexia & 2 & 6.7 & 0 & 0.0 & 3 & 5.9 & 5 & 4.6 \\
\hline Thrombocytopenia & 0 & 0.0 & 0 & 0.0 & 4 & 7.8 & 4 & 3.7 \\
\hline Diarrhoea & 1 & 3.3 & 1 & 3.7 & 0 & 0.0 & 2 & 1.9 \\
\hline Thyroid disorders & 1 & 3.3 & 0 & 0.0 & 4 & 7.9 & 5 & 4.6 \\
\hline Anxiety & 0 & 0.0 & 0 & 0.0 & 1 & 0.2 & 1 & 0.9 \\
\hline
\end{tabular}

1 infection [32,33]. In addition, few patients in the current study dropped out and the need for dose reduction was limited.

Many researchers have tried to find the possible predictive factors for SVR. Since the composition of patient samples are diverse in different studies, the results are unlikely be consistent, but evidence has shown that HCV genotype, low viral load and combination therapy are the most important factors. Because the factors related to PEG-IFN treatment interact, it is difficult to use one factor to predict the effect of therapy in chronic HCV infection [31,34].

In our analysis of patient factors, sex, age at diagnosis, BMI and mode of infection were not independent predictors of SVR, either in univariate or in logistic regression analyses. However, higher SVR rates were found in males, younger patients and those with normal BMI. This confirms the results of previous studies [18,31]. Regarding the mode of infection, $24.1 \%$ of our patients had a documented history of blood transfusion or medical exposure and $64.8 \%$ had an unknown source of infection. This is consistent with studies among Saudi patients [2,35]. This may be due to a similar pattern of community-based infection sources. Xie et al. found that the ETR, female sex, younger age and genotype were predictors of SVR. However, age and sex were not statistically correlated with SVR in the logistic model [31]. In contrast, Gad et al. reported an association with better response in males in the univariate analysis but not in the multiple regression analysis. However, their study was only on genotype 4 [29].

Within virologic factors, we studied HCV genotype, baseline viral load, ALT and AST levels and EVR. In the univariate analysis, all these factors had a significant impact on SVR. After adjustment for confounding factors in the logistic model, only baseline viral load, ALT level and EVR remained significant independent predictors of SVR.

There currently exists no systematic explanation for these genotype-specific differences in clinical outcome $[6,36]$. It is likely that genotype-specific clinical response rates are the result of a combination of host and viral factors [23]. Humans are the only known natural hosts for HCV, a virus that is estimated to be hundreds of years old [37]. This lengthy relationship may have allowed $\mathrm{HCV}$ to accumulate adaptive mutations that confer increasing resistance to the human immune system. It has been hypothesized that genotype-specific clinical response rates to interferonbased therapies are a reflection of $\mathrm{HCV}$ evolutionary adaptations to the human system [23]. The results of this study indicate that PEG-INF and weightbased RBV therapy was associated with a higher SVR rate among genotype 3 compared with genotype 1 and genotype 4 patients ( $81.5 \%$ versus $46.7 \%$ and $66.7 \%$ respectively). Although this difference did not reaching statistical significance, we think that cases of genotype $4 \mathrm{HCV}$ display intermediate sensitivity to treatment, as it they are more susceptible to treatment than the 
difficult-to-treat genotype 1 and display more inherent resistance to treatment than the genotype 3 variant. This is in accordance with other reports $[21,38]$.

Viral kinetic measurements made early in the course of therapy have been used to identify patients unlikely to achieve SVR [39]. In the current study, it was found that HCV patients with high baseline viral load were less liable to achieve SVR ( $86.8 \%$ of patients who did not achieve SVR had high baseline HCV-RNA levels as compared with $45.7 \%$ in SVR group). This percentage indicates the importance of this factor on the SVR rate and these data confirm previous studies [40,41]. Shea et al. found that low pre-treatment viral load, genotypes $2 / 3$ and EVR were predictors of SVR in univariate analysis. However, in multiple analysis, only pretreatment viral load and EVR remained as significant predictor factors [41]. This contrasts with was found by Al-Ashgar et al. in Saudi patients [18] and Kuboki et al. in Japanese patients [32]. The difference may be attributed to the fact that viral load fluctuates and a single reading may not reflect the actual viral load at the time of treatment if it is assessed at varying intervals from the date of start of treatment [15].

In the current study, a higher level of baseline ALT was found to be a predictor of non-response. In a recent study conducted in Saudi Arabia, HCV patients who achieved SVR and those who relapsed had similar ALT levels at all times of therapy, except at week 72 , when those who relapsed after ETR had significantly higher ALT levels in the univariate analysis but not in the multivariate analysis [18]. Al-Shagar et al. reported that baseline level of AST and not ALT had a significant effect on SVR [42]. The same was found by Borgia et al. in Italy [43]. This difference could be due the known correlation between these enzymes and other possible confounding effects.

In the current study, EVR was found to be a protective factor for non- sustained response. Previous studies have confirmed that the presence of EVR at week 12 can accurately identify patients unlikely to achieve SVR $[40,44]$. Consequently, the week 12 "decision point" has become widely adopted in clinical practice, with treatment goals reviewed for those patients failing to achieve EVR after 12 weeks [3]. However, Kuboki et al. found that $83 \%$ of patients without EVR at week 12 failed to achieve SVR and all patients without a virological response at week 24 failed to attain SVR. He suggested that the week 12 decision point may not apply to the Japanese population of HCV patients, and that cessation of treatment should not be considered before week 24 [32].

EVR may predict the likelihood of attaining SVR and therefore may be an earlier positive predictor of response to combination therapy $[45,46]$. Such a policy has obvious benefits in terms of costs and reductions in side-effects [41]. Data from large registration trials showed that $95 \%$ of patients with detectable HCV-RNA at week 24 of treatment failed to achieve SVR [47]. Moreover, patients who failed to achieve EVR had a negligible chance of achieving SVR $[40,44]$. Shea et al. recommended that EVR, with maintenance of full-dose HCV therapy, will identify a cohort for whom 24 weeks of treatment will successfully achieve the primary outcome [41].

Withdrawal of patients due to adverse events was lowin the present study (3.9\% overall). Dose reduction was indicated in $12.6 \%$ of patients. Adverse events were typical of those previously reported for PEG-INF therapy [32] or even lower than those reported in some other studies $[6,10,18]$. The safety profile of the combination therapy was generally similar to that reported in other studies [18,39].

We acknowledge some limitations to our study. As we relied on patient records, the data obtained might be affected by the quality of recording. As in any retrospective study, the results could be subject to bias. Nevertheless, the results are consistent with those from cohort studies. Also, due to the retrospective nature of the study, baseline liver biopsy was not performed in the majority of cases, so we could not investigate its role as a predictor of SVR. As all of the study subjects had abnormal aminotransferase levels, we could not assess the response of the patients with normal liver enzymes. Due the relatively small sample size, generalization of the results should be cautious. However, only native Kuwaiti patients, who constituted an ethnically homogenous population, were included in the study. Also, the management protocol for HCV that was adopted in the selected hospital was the same therapy applied in all government hospitals.

\section{Conclusions}

Although the dominant genotype in native Kuwaiti patients with chronic $\mathrm{HCV}$ infection is 4, other genotypes, especially type 1 and 3, occur frequently. The responsiveness of $\mathrm{HCV}$ genotype 4 to standard therapy was intermediate between HCV genotype 1 and genotype 3 . The treatment was well tolerated by most of the patients. Data about baseline viral load and ALT level in addition to EVR may serve as a decision tools for clinicians to identify patients who are unlikely to achieve SVR on PEG-INF-based therapy and to consider discontinuation of treatment in those patients, alleviating them of the side-effects and cost of additional therapy.

\section{Acknowledgements}

We are grateful to the help of Dr Medhat K. El-Shazly, Department of Medical Statistics, Medical Research Institute, University of Alexandria, Egypt. 
1. World Health Organization. Global surveillance and control of hepatitis C. Report of a WHO Consultation organized in collaboration with the Viral Hepatitis Prevention Board, Antwerp, Belgium. Journal of Viral Hepatitis, 1999, 6:35-47.

2. Akbar HO. Hepatitis C virus infection in Saudi Arabia. Saudi Journal of Gastroenterology, 2004, 10:127-131.

3. Strader DB et al. American Association for the Study of Liver Diseases practice guideline: diagnosis, management, and treatment of hepatitis C. Hepatology, 2004, 39:1147-1171.

4. National Institutes of Health Consensus Development Conference Statement June 10-12, 2002. Management of hepatitis C: 2002. Hepatology, 2002, 36(Suppl. 1):S3-20.

5. Hofmann WP et al. Ribavirin mode of action in chronic hepatitis C: from clinical use back to molecular mechanisms. Liver International, 2008, 28:1332-1343.

6. Feld JJ, Hoofnagle JH. Mechanism of action of interferon and ribavirin in treatment of hepatitis C. Nature, 2005, 436:967-972.

7. Shiffman ML et al. Peginterferon alfa-2a and ribavirin for 16 or 24 weeks in HCV genotype 2 or 3. New England Journal of Medicine, 2007, 357:124-134.

8. Yu MI et al. A randomized study of peginterferon and ribavirin for 16 weeks in patients with genotype 2 chronic hepatitis C. Gut, 2007, 56:553-559.

9. Seuzem S. Heterogenous virologic response rates to interferon-based therapy in patients with chronic hepatitis C: who responds less well? Annals of Internal Medicine, 2004, 140:370-381.

10. Manns MP et al. Peginterferon $a-2 b$ plus ribavirin compared with interferon alfa-2b plus ribavirin for initial treatment of chronic hepatitis C: a randomized trial. Lancet, 2001, 358:958-965.

11. Hadziyannis SJ et al. Peginterferon alpha 2a and ribavirin combination therapy in chronic hepatitis C: a randomized study of treatment duration and ribavirin dose. Annals of Internal Medicine, 2004, 140:346-355.

12. Kamal $S M$ et al. Peginterferon alpha-2b and ribavirin therapy in chronic hepatitis $C$ genotype 4: impact of treatment duration and viral kinetics on sustained virological response. Gut, 2005, 54:858-866.

13. Males $S$ et al. Serum alpha-fetoprotein (AFP) level predicts treatment outcome in chronic hepatitis C. Antiviral Therapy, 2007, 12:797-803.

14. Osoba AO. Hepatitis C virus genotypes in Saudi Arabia. Saudi Medical Journal, 2002, 23:7-12.

15. Hu KQ, Vierling JK, Redeker AG. Viral host and interferon related factors modulating the effect of interferon therapy for hepatitis C virus infection. Journal of Viral Hepatitis, 2001, 8:1-18.

16. Bressler BL et al. High body mass index is an independent risk factor for non response to antiviral treatment in chronic hepatitis C. Hepatology, 2003, 38:557-559.

17. Distante $\mathrm{S}$ et al. Raised serum ferritin predicts non-response to interferon and ribavirin treatment in patients with chronic hepatitis C infection. Liver, 2002, 22:269-275.

18. Al-Ashgar $\mathrm{H}$ et al. Sustained virologic response to peginterferon alfa-2a and ribavirin in 335 patients with chronic hepatitis C: A tertiary care center experience. Saudi J Gastro, 2008, 14:58-65

19. Pacsa AS et al. Genotypes of hepatitis C virus in Kuwait. Medical Principles and Practice, 2001, 10:55-57.

20. Varghese $\mathrm{R}$ et al. Treatment of chronic hepatitis $\mathrm{C}$ genotype 4 with peginterferon alpha-2a plus ribavirin. Hepato-Gastroenterology, 2009, 56:218-22.
21. Hasan $\mathrm{F}$ et al. Pegylated interferon alfa-2b plus ribavirin for the treatment of chronic hepatitis C genotype 4. American Journal of Gastroenterology, 2004, 99:1733-1737.

22. Koshy $A$ et al. Treatment of hepatitis $C$ virus genotype 4-related cirrhosis: ribavirin and interferon combination compared with interferon alone. Journal of Clinical Gastroenterology, 2002, 35:82-85.

23. Pang PS, Planet PJ, Dlenn JS. The evolution of the major hepatitis $\mathrm{C}$ genotypes correlates with clinical response to interferon therapy. PloS One, 2009, 4:e6579.

24. Mumtaz $\mathrm{K}$ et al. Distribution of hepatitis $\mathrm{C}$ genotypes and its response to treatment in Pakistani patients. Saudi Medical Journal, 2008, 29:1671-1673.

25. Zali MR et al. Hepatitis $C$ virus genotypes in the Islamic Republic of Iran: a preliminary study. Eastern Mediterranean Health Journal, 2000, 6:372-377.

26. Ray SC et al. Genetic epidemiology of hepatitis $C$ virus throughout Egypt. Journal of Infectious Diseases, 2000, 182:698-707.

27. Cross TGS, Antoniades CG, Harrison PM. Current and future management of chronic hepatitis $\mathrm{C}$ infection. Postgraduate Medical Journal, 2008, 84:172-176.

28. Leung NW. Management of viral hepatitis C. Journal of Gastroenterology and Hepatology, 2002, 17(Suppl.):S146-S154.

29. Gad RR et al. Predictors of a sustained virological response in patients with genotype 4 chronic hepatitis C. Liver International, 2008, 28:1112-1119.

30. Roulot $\mathrm{D}$ et al. Epidemiological characteristics and response to peginterferon plus ribavirin treatment of hepatitis $C$ virus genotype 4 infection. Journal of Viral Hepatitis, 2007, 14:460-467.

31. Xie $\mathrm{Y}$ et al. Predictive factors for sustained response to interferon treatment in patients with chronic hepatitis C: a randomized, open, and multi-center controlled trial. Hepatobiliary and Pancreatic Diseases International, 2005, 4:213-219.

32. Kuboki $\mathrm{M}$ et al. Peginterferon a-2a $(40 \mathrm{KD})$ plus ribvirin for the treatment of chronic hepatitis $\mathrm{C}$ in Japanese patients. Journal of Gastroenterology and Hepatology, 2007, 22:645-652.

33. Dev AT et al. Southeast Asian patients with chronic hepatitis C: the impact of novel genotypes and race on treatment outcome. Hepatology, 2002, 36:1259-1265.

34. Orito E. HCV genotype as a predictor of response to interferon therapy in patients with chronic hepatitis C. Japanese Journal of Clinical Medicine, 2001, 59:1356-1362.

35. Shobokshi OA, Serebour FE, Skakni LI. Hepatitis C genotypes/ subtypes among chronic hepatitis patients in Saudi Arabia. Saudi Medical Journal, 2003, 24:S87-S91.

36. Chisari FV. Unscrambling hepatitis C virus-host interaction. Nature, 2005, 436:930-932.

37. Bybus OG et al. Genetic history of hepatitis C virus in East Asia. Journal of Virology, 2009, 83:1071-1082.

38. Kamal S. Improving outcome in patients with hepatitis $\mathrm{C}$ virus genotype 4. American Journal of Gastroenterology, 2007, 102:2582-2588.

39. Di Bisceglie AM et al. Early virologic response after peginterferon alpha-2a plus ribavirin or peginterferon alpha- $2 \mathrm{~b}$ plus ribavirin treatment in patients with chronic hepatitis C. Journal of Viral Hepatitis, 2007, 14:721-729.

40. Fried MW et al. Peginterferon a-2a plus ribavirin for chronic hepatitis C virus infection. New England Journal of Medicine, 2002, 347:975-982.

41. Shea DO et al. Role of rapid virological response in prediction of sustained virological response to Peg-IFN plus ribavirin in 
HCV/HIV co-infected individuals. Journal of Viral Hepatitis, 2008, 15:482-449.

42. Al-Shgar $\mathrm{H}$ et al. Predictors of sustained virological response to a 48-week course of pegylated interferon alfa-2a and ribavirin in patients infected with hepatitis $C$ virus genotype 4. Annals of Saudi Medicine, 2009, 29:4-14.

43. Borgia $G$ et al. Homocysteine levels and sustained virological response to pegylated-interferon a2b plus ribavirin therapy for chronic hepatitis C: a retrospective study. Liver International, 2009, 29:248-252.

44. Davis GL et al. Early virologic response to treatment with peginterferon alfa- $2 \mathrm{~b}$ plus ribavirin in patients with chronic hepatitis C. Hepatology (Baltimore, Md.), 2003, 38:645-652.
45. Ferenci $\mathrm{P}$ et al. Predicting sustained virological response in chronic hepatitis $\mathrm{C}$ patients treated with peginterferon alfa-2b (40KD)/ribavirin. Journal of Hepatology, 2005, 43:425-433.

46. Ferenci P. Predicting the therapeutic response in patients with chronic hepatitis C: the role of viral kinetic studies. Journal of Antimicrobial Chemotherapy, 2004, 53:15-18.

47. McHutchison JG et al. predicting response to initial therapy with interferon plus ribavirin in chronic hepatitis $\mathrm{C}$ using serum HCV RNA results during therapy. Journal of Viral Hepatitis, 2001, 8:414-420.

\section{Hepatitis C}

No vaccine exists to prevent hepatitis $\mathrm{C}$ virus ( $\mathrm{HCV}$ ) infection, unlike those for hepatitis $\mathrm{A}$ and $\mathrm{B}$ virus. The risk of infection can be reduced by avoiding: unnecessary and unsafe injections; unsafe blood products; unsafe sharps waste collection and disposal; use of illicit drugs and sharing of injection equipment; unprotected sex with HCVinfected persons; sharing of sharp personal items that may be contaminated with infected blood; tattoos, piercings and acupuncture performed with contaminated equipment.

If a person is infected with $\mathrm{HCV}$, they should: receive education and counselling on options for care and treatement; be immunized with hepatitis A and B vaccine, to prevent co-infection from these hepatitis viruses, to protect their liver; get early and appropriate medical management including antiviral therapy if appropriate; and get regular monitoring for early diagnosis of liver disease.

Interferon and ribaviron-based therapy has been the mainstay of HCV treatment. Unfortunately, interferon is not widely available globally, is not always well tolerated, some genotypes respond better than others, and many people who take it do not finish their treatment. Fortunately, scientific advances and intense research and development have led to the development of many new oral antiviral drugs for HCV infection. The future seems to hold great promise for HCV specific oral drugs that will be more effective and better tolerated. Much still needs to be done to ensure that these advances lead to greater access and treatment globally.

Source: WHO Fact sheet No. 164, June 2011

http://www.who.int/mediacentre/factsheets/fs164/en/index.html 